\title{
Convergence and stability of modified Ishikawa iteration sequence with errors
}

Liping Yang ${ }^{1 *}$ and Shiguo Peng ${ }^{2}$

"Correspondence: yanglping2003@126.com

'School of Applied Mathematics, Guangdong University of

Technology, Guangzhou, 510520, China

Full list of author information is available at the end of the article

\begin{abstract}
We show some stability and convergence theorems of the modified Ishikawa iterative sequence with errors for a strongly successively pseudocontractive and strictly asymptotically pseudocontractive mapping in a real Banach space. Additionally, we prove that if $T$ is a uniformly Lipschitzian strongly accretive mapping, the modified Ishikawa iteration sequence with errors converges strongly to the unique solution of the equation $T x=f$. The main results of this paper improve and extend the known results in the current literature.

MSC: Primary 47H09; 47H10; secondary 47J25

Keywords: modified Ishikawa iteration sequence with errors; strongly successively pseudocontractive mapping; uniformly Lipschitzian mapping; almost $T$-stability; weak T-stability
\end{abstract}

\section{Introduction}

Developments in fixed point theory reflect that the iterative construction of fixed points is proposed and vigorously analyzed for various classes of maps in different spaces. The class of pseudocontractive mappings in their relation with iteration procedures has been studied by several researchers under suitable conditions; for more details, see [1-3] and the references therein. Also, the class of nonexpansive mappings via iteration methods has extensively been studied in this regard; see Tan and $\mathrm{Xu}$ [4]. The class of strongly pseudocontractive mappings has been studied by many researchers (see [5-7]) under certain conditions. Stability results established in metric space, normed linear space, and Banach space settings are available in the literature. There are several authors whose contributions are of colossal value in the study of stability of the fixed point iterative procedures: Imoru and Olatinwo [8], Olatinwo [9], Haghi et al. [10], Olatinwo and Postolache [11]. Reich and Zaslavski [12] in Chapter 2 established the existence and uniqueness of a fixed point for a generic mapping, convergence of the iterates of a nonexpansive mapping, stability of the fixed point under small perturbations of a mapping, convergence of Krasnosel'skiiMann iterations of nonexpansive mappings, generic power convergence of order preserving mappings, and existence and uniqueness of positive eigenvalues and eigenvectors of order-preserving linear operators. They also studied the convergence of iterates of nonexpansive mappings in the presence of computational errors in this chapter. Harker and Hicks in [13] showed how a stability sequence could arise in practice and demonstrated the importance of investigating the stability of various iterative sequences for some kinds of nonlinear mappings.

@2014 Yang and Peng; licensee Springer. This is an Open Access article distributed under the terms of the Creative Commons Attribution License (http://creativecommons.org/licenses/by/2.0), which permits unrestricted use, distribution, and reproduction in any medium, provided the original work is properly cited. 
The purpose in this paper is to study the modified Ishikawa iteration sequence with errors converging strongly to a fixed point of the uniformly Lipschitzian strongly successively pseudocontractive mapping under the lack of some conditions. On the other hand, the authors show that the modified Ishikawa iteration sequence with errors converges strongly to the unique solution of the equation $T x=f$ if $T$ is a Lipschitzian strongly accretive mapping. The results of this paper improve and extend some recent results.

\section{Preliminaries}

Throughout this paper, we assume that $E$ is a real Banach space with dual $E^{*}$. Suppose that $\langle\cdot, \cdot\rangle$ is the dual pair between $E$ and $E^{*}$, and $J: E \rightarrow 2^{E^{*}}$ is the normalized duality mapping defined by

$$
J(x)=\left\{f \in E^{*}:\langle x, f\rangle=\|x\|^{2},\|f\|=\|x\|\right\}, \quad \forall x \in E .
$$

First, we recall some concepts. A mapping $T: E \rightarrow E$ is said to be:

(i) uniformly Lipschizian if there exists a constant $L>0$ such that

$$
\left\|T^{n} x-T^{n} y\right\| \leq L\|x-y\| \quad \text { for all } x, y \in E, n \geq 1
$$

(ii) strongly successively pseudocontractive if for every $x, y \in E$ there exist $t>1$ and $j(x-y) \in J(x-y)$ such that

$$
\left\langle T^{n} x-T^{n} y, j(x-y)\right\rangle \leq \frac{1}{t}\|x-y\|^{2} \quad \text { for all } n \geq 1 ;
$$

(iii) strongly pseudocontractive if for every $x, y \in E$ there exist $t>1$ and $j(x-y) \in J(x-y)$ such that

$$
\langle T x-T y, j(x-y)\rangle \leq \frac{1}{t}\|x-y\|^{2} .
$$

Example 2.1 Let $E=R=(-\infty, \infty)$ with the usual norm. Take $K=[0,1]$ and define $T$ : $K \rightarrow K$ by

$$
T x= \begin{cases}0 & \text { if } x=0 \\ \frac{1}{9} & \text { if } x=1, \\ x-\frac{1}{3^{n+1}} & \text { if } \frac{1}{3^{n+1}} \leq x<\frac{1}{3}\left(\frac{1}{3^{n+1}}+\frac{1}{3^{n}}\right) \\ \frac{1}{3^{n}}-x & \text { if } \frac{1}{3}\left(\frac{1}{3^{n+1}}+\frac{1}{3^{n}}\right) \leq x<\frac{1}{3^{n}}\end{cases}
$$

for all $n \geq 0$. Then $F(T)=\{0\}$ and $T$ is not continuous at $x=1$. We can verify that

$$
T x \leq \frac{1}{3} x, \quad x \in K
$$

Thus $T^{2}$ is continuous in $K$ and $T^{2} K \subset\left[0,3^{-n}\right]$ for all $n \geq 1$. Then for any $x \in K$, there exists $j(x-0) \in J(x-0)$ satisfying

$$
\left\langle T^{n} x-T^{n} 0, j(x-0)\right\rangle=T^{n} x \cdot x \leq \frac{1}{3}\|x\|^{2}
$$

for all $n \geq 1$. That is, $T$ is a strongly successively pseudocontractive mapping. 
Lemma 2.2 (see [14, Lemma 1.1]) Let E be a Banach space and $x, y \in E$. Then $\|x\| \leq \| x+$ $\gamma y \|$ for all $\gamma>0$ if and only if there exists $j(x) \in J(x)$ such that $\operatorname{Re}\langle y, j(x)\rangle \geq 0$.

In the sequel, let $k=\frac{t-1}{t}$, where $t$ is the constant appearing in (2.1). It follows from (2.1) that

$$
\left\langle\left((1-k) I-T^{n}\right) x-\left((1-k) I-T^{n}\right) y, j(x-y)\right) \geq 0 .
$$

Therefore, it follows from Lemma 2.2 and (2.3) that the definition of a strongly successively pseudocontractive mapping is equivalent to the following definition.

Definition 2.3 $T$ is strongly successively pseudocontractive if there exists $t>1$ such that

$$
\|x-y\| \leq\left\|x-y+s\left[\left((1-k) I-T^{n}\right) x-\left((1-k) I-T^{n}\right) y\right]\right\|
$$

for all $x, y \in E, s>0$ and $n \geq 1$.

Definition 2.4 Let $T: E \rightarrow E$ be a mapping. For a given $x_{0} \in E .\left\{a_{n}\right\},\left\{b_{n}\right\}$ are sequences in $[0,1]$, and $\left\{u_{n}\right\},\left\{v_{n}\right\}$ are sequences in $E$. The sequence $\left\{x_{n}\right\} \subset E$ defined by

$$
\left\{\begin{array}{l}
x_{n+1}=\left(1-a_{n}\right) x_{n}+a_{n} T^{n} z_{n}+u_{n}, \\
z_{n}=\left(1-b_{n}\right) x_{n}+b_{n} T^{n} x_{n}+v_{n}, \quad n=0,1, \ldots,
\end{array}\right.
$$

is said to be a modified Ishikawa iteration sequence with errors.

The following lemmas will be needed in proving our main results.

Lemma 2.5 (see [15]) Let $\left\{\lambda_{n}\right\},\left\{\mu_{n}\right\},\left\{c_{n}\right\}$ be nonnegative real sequences satisfying the inequality

$$
\lambda_{n+1} \leq\left(1+\mu_{n}\right) \lambda_{n}+c_{n}, \quad \forall n \geq 1 .
$$

If $\sum_{n=1}^{\infty} \mu_{n}<\infty$ and $\sum_{n=1}^{\infty} c_{n}<\infty$, then (i) $\lim _{n \rightarrow \infty} \lambda_{n}$ exists, and (ii) in particular, if $\left\{\lambda_{n}\right\}$ has a subsequence $\left\{\lambda_{n_{k}}\right\}$ converging to 0 , then $\lim _{n \rightarrow \infty} \lambda_{n}=0$.

From Lemma 2.5 we have the following.

Lemma 2.6 Let $\left\{\lambda_{n}\right\},\left\{\mu_{n}\right\},\left\{d_{n}\right\}$ be nonnegative real sequences satisfying

$$
\lambda_{n+1} \leq\left(1-t_{n}\right) \lambda_{n}+\mu_{n} \lambda_{n}+c_{n}+d_{n}, \quad \forall n \geq 1,
$$

where $\left\{t_{n}\right\}$ is a sequence in $[0,1]$ such that $\sum_{n=1}^{\infty} t_{n}=\infty, \sum_{n=1}^{\infty} \mu_{n}<\infty, \sum_{n=1}^{\infty} c_{n}<\infty$ and $d_{n}=o\left(t_{n}\right)$. Then $\lambda_{n} \rightarrow 0$ as $n \rightarrow \infty$.

Proof Since $d_{n}=o\left(t_{n}\right)$, there exists a natural number $n_{0}$ such that $d_{n} \leq \frac{t_{n} \lambda_{n}}{2}$ for $n \geq n_{0}$. It follows from (2.6) that

$$
\lambda_{n+1} \leq\left(1-\frac{t_{n}}{2}\right) \lambda_{n}+\mu_{n} \lambda_{n}+c_{n} \leq\left(1+\mu_{n}\right) \lambda_{n}+c_{n}, \quad \forall n \geq n_{0} .
$$

By Lemma 2.5, we see that $\lim _{n \rightarrow \infty} \lambda_{n}$ exists. Therefore, there exists $D>0$ such that $\lambda_{n} \leq D$. 
Let $\lim _{n \rightarrow \infty} \lambda_{n}=\delta$, then $\delta=0$. Indeed, if $\delta>0$, there exists a natural number $N_{0}$ such that $\lambda_{n} \geq(\delta / 2), d_{n} \leq\left(t_{n} \lambda_{n}\right) / 2$ for $n \geq N_{0}$. It follows from (2.6) that

$$
\lambda_{n+1} \leq \lambda_{n}-t_{n} \lambda_{n}+\mu_{n} \lambda_{n}+c_{n}+d_{n} \leq \lambda_{n}-\frac{t_{n} \lambda_{n}}{2}+D \mu_{n}+c_{n}
$$

This implies $\frac{\delta t_{n}}{4} \leq \frac{\lambda_{n} t_{n}}{2} \leq \lambda_{n}-\lambda_{n+1}+D \mu_{n}+c_{n}, \forall n \geq N_{0}$. Therefore,

$$
\frac{\delta}{4} \sum_{i=N_{0}}^{n} t_{n} \leq \lambda_{N_{0}}+D \sum_{i=N_{0}}^{n} \mu_{j}+\sum_{i=N_{0}}^{n} c_{n} .
$$

Note that $\sum_{n=1}^{\infty} \mu_{n}<\infty$ and $\sum_{n=1}^{\infty} c_{n}<\infty$, and we have $\sum_{n=1}^{\infty} t_{n}<\infty$, a contradiction with $\sum_{n=1}^{\infty} t_{n}=\infty$. Then $\lim _{n \rightarrow \infty} \lambda_{n}=0$. This completes the proof of Lemma 2.6.

Let $E$ be a Banach space and $T$ a self-map of $E$. Suppose $x_{0} \in E$ and $x_{n+1}=f\left(x_{n}, T\right)$ defines an iteration procedure which yields a sequence of points $\left\{x_{n}\right\} \subset E$. Let $F(T)=\{p \in E: T p=$ $p\} \neq \emptyset$ denote the fixed point of $T$ and let $\left\{x_{n}\right\}$ converge to a fixed point $p$ of $T$. Let $\left\{y_{n}\right\} \subset E$ and let $\varepsilon_{n}=\left\|y_{n+1}-f\left(y_{n}, T\right)\right\|$ be a sequence in $[0, \infty)$.

Definition 2.7 (see $[13,16,17]$ ) If $\lim _{n \rightarrow \infty} \varepsilon_{n}=0$ implies that $\lim _{n \rightarrow \infty} y_{n}=p$, then the iteration procedure defined by $x_{n+1}=f\left(x_{n}, T\right)$ is said to be $T$-stable. If $\sum_{n=0}^{\infty} \varepsilon_{n}<\infty$ implies $\lim _{n \rightarrow \infty} y_{n}=p$, then the iteration procedure defined by $x_{n+1}=f\left(x_{n}, T\right)$ is said to be almost $T$-stable.

\section{Main results}

Theorem 3.1 Let $T: E \rightarrow E$ be a uniformly Lipschitzian and strongly successively pseudocontractive mapping with $F(T) \neq \emptyset$. Let $\left\{x_{n}\right\}$ be defined by $(2.5)$ and $\left\{a_{n}\right\},\left\{b_{n}\right\} \subset[0,1]$ and $\left\{u_{n}\right\},\left\{v_{n}\right\} \subset E$ satisfying the conditions:

(i) $\left\|u_{n}\right\|=o\left(a_{n}\right),\left\|v_{n}\right\| \rightarrow 0$ as $n \rightarrow \infty ; \sum_{n=1}^{\infty} a_{n}=\infty$;

(ii) $\lim _{n \rightarrow \infty} \sup a_{n}<k /\left((L+1)^{3}+2\right)$ and $\sum_{n=1}^{\infty} a_{n} b_{n}<\infty$.

Suppose $\left\{y_{n}\right\} \subset E$ and define $\left\{\varepsilon_{n}\right\}$ by

$$
\begin{aligned}
& s_{n}=\left(1-b_{n}\right) y_{n}+b_{n} T^{n} y_{n}+v_{n}, \\
& \varepsilon_{n}=\left\|y_{n+1}-\left(1-a_{n}\right) y_{n}-a_{n} T^{n} s_{n}-u_{n}\right\|, \quad n \geq 0 .
\end{aligned}
$$

Then the following assertions hold:

(1) $\left\{x_{n}\right\}$ converges strongly to a unique fixed point of $T$ in $E$;

(2) $\left\{x_{n}\right\}$ is almost $T$-stable;

(3) if $\lim _{n \rightarrow \infty} \varepsilon_{n} / a_{n}=0$ implies $\lim _{n \rightarrow \infty} y_{n}=p$, then the iteration procedure defined by $x_{n+1}=f\left(x_{n}, T\right)$ is said to be a weakly $T$-stable. Thus $\left\{x_{n}\right\}$ is also weakly $T$-stable.

Proof We will show that $F(T)$ is a singleton. Indeed, if $p_{1}, p_{2} \in F(T)$, by the definition of strongly successively pseudocontractive of $T$, there exists a $j\left(p_{1}-p_{2}\right) \in J\left(p_{1}-p_{2}\right)$ such that

$$
\left\|p_{1}-p_{2}\right\|^{2}=\left\langle T p_{1}-T p_{2}, j\left(p_{1}-p_{2}\right)\right\rangle=\left\langle T^{n} p_{1}-T^{n} p_{2}, j\left(p_{1}-p_{2}\right)\right\rangle \leq \frac{1}{t}\left\|p_{1}-p_{2}\right\|^{2},
$$

and, since $t>1$, this implies that $p_{1}=p_{2}$. 
It follows from $(2.5)$ that

$$
\begin{aligned}
&\left\|z_{n}-p\right\|=\left\|\left(1-b_{n}\right)\left(x_{n}-p\right)+b_{n}\left(T^{n} x_{n}-p\right)+v_{n}\right\| \\
& \leq\left(1-b_{n}\right)\left\|x_{n}-p\right\|+b_{n}\left\|T^{n} x_{n}-p\right\|+\left\|v_{n}\right\| \\
& \leq\left\|x_{n}-p\right\|+\left\|T^{n} x_{n}-p\right\|+\left\|v_{n}\right\| \\
& \leq(L+1)\left\|x_{n}-p\right\|+\left\|v_{n}\right\|, \\
&\left\|x_{n}-T^{n} z_{n}\right\| \leq\left\|x_{n}-p\right\|+L\left\|z_{n}-p\right\| \leq(1+L(L+1))\left\|x_{n}-p\right\|+L\left\|v_{n}\right\| .
\end{aligned}
$$

It follows from (2.5), (3.1), and (3.2) that

$$
\begin{aligned}
\left\|T^{n} x_{n+1}-T^{n} z_{n}\right\| \leq & L\left\|x_{n+1}-z_{n}\right\|=L\left\|\left(x_{n}-z_{n}\right)+a_{n}\left(T^{n} z_{n}-x_{n}\right)+u_{n}\right\| \\
\leq & L\left\|x_{n}-z_{n}\right\|+L a_{n}\left\|T^{n} z_{n}-x_{n}\right\|+L\left\|u_{n}\right\| \\
& =L\left\|b_{n}\left(x_{n}-T^{n} x_{n}\right)-v_{n}\right\|+L a_{n}\left\|T^{n} z_{n}-x_{n}\right\|+L\left\|u_{n}\right\| \\
\leq & L b_{n}\left\|x_{n}-T^{n} x_{n}\right\|+L\left\|v_{n}\right\|+L a_{n}\left\|T^{n} z_{n}-x_{n}\right\|+u_{n} \\
\leq & L b_{n}\left\|x_{n}-T^{n} x_{n}\right\|+L\left\|v_{n}\right\|+L a_{n}\left\|T^{n} z_{n}-z_{n}\right\|+L\left\|u_{n}\right\| \\
\leq & {\left[L(L+1) b_{n}+L\left(L^{2}+L+1\right) a_{n}\right]\left\|x_{n}-p\right\| } \\
& +L(1+L)\left\|v_{n}\right\|+L\left\|u_{n}\right\| .
\end{aligned}
$$

It follows from $(2.5)$ that

$$
\begin{aligned}
x_{n}= & x_{n+1}+a_{n} x_{n}-a_{n} T^{n} z_{n}-u_{n} \\
= & x_{n+1}+(2-k) a_{n} x_{n}-a_{n} T^{n} z_{n}-(1-k) a_{n} x_{n}-u_{n} \\
= & x_{n+1}+(2-k) a_{n}\left(x_{n+1}+a_{n}\left(x_{n}-T^{n} z_{n}\right)-u_{n}\right)-a_{n} T^{n} z_{n}-(1-k) a_{n} x_{n}-u_{n} \\
= & \left(1+a_{n}\right) x_{n+1}+(1-k) a_{n} x_{n+1}-a_{n} T^{n} x_{n+1}+a_{n} T^{n} x_{n+1}-a_{n} T^{n} z_{n} \\
& +(2-k) a_{n}^{2}\left(x_{n}-T^{n} z_{n}\right)-(1-k) a_{n} x_{n}-(2-k) a_{n} u_{n}-u_{n} \\
= & \left(1+a_{n}\right) x_{n+1}+a_{n}\left(I-T^{n}-k I\right) x_{n+1}-(1-k) a_{n} x_{n} \\
& +(2-k) a_{n}^{2}\left(x_{n}-T^{n} z_{n}\right)+a_{n}\left(T^{n} x_{n+1}-T^{n} z_{n}\right)-\left[(2-k) a_{n}+1\right] u_{n} .
\end{aligned}
$$

For $p \in F(T)$, we have $p=\left(1+a_{n}\right) p+a_{n}\left(I-T^{n}-k I\right) p-(1-k) a_{n} p$. Therefore, we get

$$
\begin{aligned}
x_{n}-p= & \left(1+a_{n}\right)\left(x_{n+1}-p\right)+a_{n}\left[\left(I-T^{n}-k I\right) x_{n+1}-\left(I-T^{n}-k I\right) p\right] \\
& -(1-k) a_{n}\left(x_{n}-p\right)+(2-k) a_{n}^{2}\left(x_{n}-T^{n} z_{n}\right) \\
& +a_{n}\left(T^{n} x_{n+1}-T^{n} z_{n}\right)-\left[(2-k) a_{n}+1\right] u_{n} .
\end{aligned}
$$

It follows from (3.4) and (2.4) that

$$
\begin{aligned}
\left\|x_{n}-p\right\|= & \|\left(1+a_{n}\right)\left(x_{n+1}-p\right)+a_{n}\left[\left(I-T^{n}-k I\right) x_{n+1}-\left(I-T^{n}-k I\right) p\right] \\
& -(1-k) a_{n}\left(x_{n}-p\right)+(2-k) a_{n}^{2}\left(x_{n}-T^{n} z_{n}\right)
\end{aligned}
$$




$$
\begin{aligned}
& +a_{n}\left(T^{n} x_{n+1}-T^{n} z_{n}\right)-\left[(2-k) a_{n}+1\right] u_{n} \| \\
\geq & \left(1+a_{n}\right)\left\|x_{n+1}-p\right\|-(1-k) a_{n}\left\|x_{n}-p\right\| \\
& -(2-k) a_{n}^{2}\left\|x_{n}-T^{n} z_{n}\right\| \\
& -a_{n}\left\|T^{n} x_{n+1}-T^{n} z_{n}\right\|-\left[(2-k) a_{n}+1\right]\left\|u_{n}\right\| \\
\geq & \left(1+a_{n}\right)\left\|x_{n+1}-p\right\|-(1-k) a_{n}\left\|x_{n}-p\right\| \\
& -(2-k) a_{n}^{2}\left[\left(1+L+L^{2}\right)\left\|x_{n}-p\right\|+L\left\|v_{n}\right\|\right] \\
& -a_{n}\left[L(L+1) b_{n}+L\left(L^{2}+L+1\right) a_{n}\right]\left\|x_{n}-p\right\| \\
& -L a_{n}\left\|u_{n}\right\|-L(L+1) a_{n}\left\|v_{n}\right\|-\left[(2-k) a_{n}+1\right]\left\|u_{n}\right\| .
\end{aligned}
$$

Since $\left(1+a_{n}\right)^{-1} \leq 1,\left(1+a_{n}\right)^{-1} \leq 1-a_{n}+a_{n}^{2}$, and $\left(1+(1-k) a_{n}\right)\left(1-a_{n}+a_{n}^{2}\right)=1-k a_{n}+$ $k a_{n}^{2}+(1-k) a_{n}^{3} \leq 1-k a_{n}+k a_{n}^{2}+(1-k) a_{n}^{2}=1-k a_{n}+a_{n}^{2}$, we have

$$
\begin{aligned}
\left\|x_{n+1}-p\right\| \leq & \frac{1+(1-k) a_{n}}{1+a_{n}}\left\|x_{n}-p\right\| \\
& +\left[L(L+1) a_{n} b_{n}+\left(L^{3}+3 L^{2}+3 L+2\right) a_{n}^{2}\right]\left\|x_{n}-p\right\| \\
& +(L+3)\left\|u_{n}\right\|+L(L+3) a_{n}\left\|v_{n}\right\| \\
\leq & \left(1+(1-k) a_{n}\right)\left(1-a_{n}+a_{n}^{2}\right)\left\|x_{n}-p\right\| \\
& +\left[L(L+1) a_{n} b_{n}+\left(L^{3}+3 L^{2}+3 L+2\right) a_{n}^{2}\right]\left\|x_{n}-p\right\| \\
& +(L+3)\left\|u_{n}\right\|+L(L+3) a_{n}\left\|v_{n}\right\| \\
\leq & \left(1-k a_{n}\right)\left\|x_{n}-p\right\| \\
& +\left[L(L+1) a_{n} b_{n}+\left(L^{3}+3 L^{2}+3 L+3\right) a_{n}^{2}\right]\left\|x_{n}-p\right\| \\
& +(L+3)\left\|u_{n}\right\|+L(L+3) a_{n}\left\|v_{n}\right\| .
\end{aligned}
$$

Note that $\lim _{n \rightarrow \infty} \sup a_{n}<k /\left((L+1)^{3}+2\right)$, then there exists a natural number $N_{1}$ such that $\gamma=\sup _{n \geq N_{1}} a_{n}<k /\left((L+1)^{3}+2\right)$. It follows from (3.5) that

$$
\begin{aligned}
\left\|x_{n+1}-p\right\| \leq & {\left[1-\left(k-\gamma\left((L+1)^{3}+2\right)\right) a_{n}\right]\left\|x_{n}-p\right\| } \\
& +L(L+1) a_{n} b_{n}\left\|x_{n}-p\right\|+(L+3)\left\|u_{n}\right\|+L(L+3) a_{n}\left\|v_{n}\right\|
\end{aligned}
$$

holds for $n \geq N_{1}$. Let $\lambda_{n}:=\left\|x_{n}-p\right\|, \mu_{n}:=L(L+1) a_{n} b_{n}, c_{n}=0, d_{n}:=(L+3)\left\|u_{n}\right\|+L(L+$ 3) $a_{n}\left\|v_{n}\right\|, t_{n}:=\left(k-\gamma\left((L+1)^{3}+2\right)\right) a_{n}$. Thus, (3.6) becomes

$$
\lambda_{n+1} \leq\left(1-t_{n}\right) \lambda_{n}+\mu_{n} \lambda_{n}+d_{n}, \quad \forall n \geq N_{1}
$$

Since $\sum_{n=1}^{\infty} \mu_{n}<\infty, d_{n}=o\left(t_{n}\right)$, it follows from Lemma 2.6 that we have $\lim _{n \rightarrow \infty} \lambda_{n}=0$. That is, $\left\{x_{n}\right\}$ converges strongly to $p$.

Next, we prove the conclusion (2). Let

$$
p_{n}=\left(1-a_{n}\right) y_{n}+a_{n} T^{n} s_{n}+u_{n} .
$$


For $p \in F(T)$, we have

$$
\begin{aligned}
\left\|y_{n+1}-p\right\| & =\left\|y_{n+1}-\left(1-a_{n}\right) y_{n}-a_{n} T^{n} s_{n}-u_{n}+\left(1-a_{n}\right) y_{n}+a_{n} T^{n} s_{n}+u_{n}-p\right\| \\
& \leq \varepsilon_{n}+\left\|p_{n}-p\right\| .
\end{aligned}
$$

It follows from (3.7) that

$$
\begin{aligned}
y_{n}= & p_{n}+a_{n} y_{n}-a_{n} T^{n} s_{n}-u_{n} \\
= & \left(1+a_{n}\right) p_{n}+a_{n}\left(I-T^{n}-k I\right) p_{n}-(1-k) a_{n} y_{n} \\
& +(2-k) a_{n}^{2}\left(y_{n}-T^{n} s_{n}\right)+a_{n}\left(T^{n} p_{n}-T^{n} s_{n}\right)-\left[(2-k) a_{n}+1\right] u_{n} .
\end{aligned}
$$

By using a similar method to proving (3.6), we can prove that

$$
\begin{aligned}
\left\|p_{n}-p\right\| \leq[ & {\left[1-\left(k-\gamma\left((L+1)^{3}+2\right)\right) a_{n}\right]\left\|y_{n}-p\right\| } \\
& +L(L+1) a_{n} b_{n}\left\|y_{n}-p\right\|+(L+3)\left\|u_{n}\right\|+L(L+3) a_{n}\left\|v_{n}\right\| .
\end{aligned}
$$

Substituting (3.9) into (3.8) for $n \geq N_{0}$ we get

$$
\begin{aligned}
\left\|y_{n+1}-p\right\| \leq & {\left[1-\left(k-\gamma\left((L+1)^{3}+2\right)\right) a_{n}\right]\left\|y_{n}-p\right\| } \\
& +L(L+1) a_{n} b_{n}\left\|y_{n}-p\right\|+(L+3)\left\|u_{n}\right\| \\
& +L(L+3) a_{n}\left\|v_{n}\right\|+\varepsilon_{n} .
\end{aligned}
$$

If $\sum_{n=1}^{\infty} \varepsilon_{n}<\infty$, setting $\lambda_{n}:=\left\|y_{n}-p\right\|, \mu_{n}:=L(L+1) a_{n} b_{n}, c_{n}=\varepsilon_{n}, d_{n}:=(L+3)\left\|u_{n}\right\|+L(L+$ 3) $a_{n}\left\|v_{n}\right\|, t_{n}:=\left(k-\gamma\left((L+1)^{3}+2\right)\right) a_{n}$ in Lemma 2.6, we have $y_{n} \rightarrow p$ as $n \rightarrow \infty$, i.e., $\left\{x_{n}\right\}$ is almost $T$-stable.

If $\lim _{n \rightarrow \infty} \frac{\varepsilon_{n}}{a_{n}}=0$, setting $\lambda_{n}:=\left\|y_{n}-p\right\|, \mu_{n}:=L(L+1) a_{n} b_{n}, c_{n}=0, d_{n}:=(L+3)\left\|u_{n}\right\|+$ $L(L+3) a_{n}\left\|v_{n}\right\|+\varepsilon_{n}, t_{n}:=\left(k-\gamma\left((L+1)^{3}+2\right)\right) a_{n}$ in Lemma 2.6, we have $y_{n} \rightarrow p$ as $n \rightarrow \infty$, i.e., $\left\{x_{n}\right\}$ is weakly $T$-stable. This completes the proof.

Similar to the proof of Theorem 3.1, we have the following.

Theorem 3.2 Let $T: E \rightarrow$ E be a uniformly Lipschitzian and strictly asymptotically pseudocontractive mapping with $F(T) \neq \emptyset$. Let $\left\{x_{n}\right\}$ be defined by (2.5). Assume that $\left\{a_{n}\right\},\left\{b_{n}\right\} \subset$ $[0,1]$ and $\left\{u_{n}\right\},\left\{v_{n}\right\} \subset$ E satisfy the conditions:

(i) $\left\|u_{n}\right\|=o\left(a_{n}\right),\left\|v_{n}\right\| \rightarrow 0$ as $n \rightarrow \infty$;

(ii) there exists $\delta \in(0,1-k)$ such that $\lim _{n \rightarrow \infty} \sup a_{n}<\delta /\left((L+1)^{3}+2\right)$;

(iii) $\sum_{n=1}^{\infty} a_{n} b_{n}<\infty$ and $\sum_{n=1}^{\infty} a_{n}=\infty$.

Suppose $\left\{y_{n}\right\} \subset E$ and define $\left\{\varepsilon_{n}\right\}$ by

$$
\begin{aligned}
& s_{n}=\left(1-b_{n}\right) y_{n}+b_{n} T^{n} y_{n}+v_{n}, \\
& \varepsilon_{n}=\left\|y_{n+1}-\left(1-a_{n}\right) y_{n}-a_{n} T^{n} s_{n}-u_{n}\right\|, \quad n \geq 0 .
\end{aligned}
$$

Then the following assertions hold: 
(1) $\left\{x_{n}\right\}$ converges strongly to a unique fixed point of $T$ in $E$;

(2) $\left\{x_{n}\right\}$ is both almost $T$-stable and weakly $T$-stable.

Theorem 3.3 Let $T: E \rightarrow E$ be a Lipschitzian and strongly accretive mapping. Let $\left\{a_{n}\right\},\left\{b_{n}\right\} \subset[0,1]$, and $\left\{u_{n}\right\},\left\{v_{n}\right\} \subset E$ satisfy the conditions:

(i) $\left\|u_{n}\right\|=o\left(a_{n}\right),\left\|v_{n}\right\| \rightarrow 0$ as $n \rightarrow \infty$;

(ii) $\lim _{n \rightarrow \infty} \sup a_{n}<k /\left((L+1)^{3}+2\right)$, where $k$ is the constant of strongly accretive mapping $T$, and $L$ is the Lipschitzian constant of mapping $I-T$;

(iii) $\sum_{n=1}^{\infty} a_{n} b_{n}<\infty$ and $\sum_{n=1}^{\infty} a_{n}=\infty$.

For arbitrary $x_{0} \in E$, the sequence $\left\{x_{n}\right\}$ defined by

$$
\left\{\begin{array}{l}
x_{n+1}=\left(1-a_{n}\right) x_{n}+a_{n}\left(f+(I-T) z_{n}\right)+u_{n}, \\
z_{n}=\left(1-b_{n}\right) x_{n}+b_{n}\left(f+(I-T) x_{n}\right)+v_{n}, \quad \forall n \geq 0
\end{array}\right.
$$

converges strongly to a solution $p$ of $T x=f$.

Proof From the result of [5], we obtain the existence of a solution for $T x=f$. Since $T$ is strongly accretive with a constant $k \in(0,1)$, we can prove that the solution of $T x=f$ is unique. Define $S x=f+(I-T) x$, then $S$ is a strongly pseudocontractive mapping and has a fixed point $p$, and it is also a Lipschitzian mapping with a constant $L$. For all $x, y \in E$, there exists $s>0$ such that

$$
\|x-y\| \leq\|x-y+s[((1-k) I-S) x-((1-k) I-S) y]\| .
$$

The rest of the proof is similar to the proof of Theorem 3.1. This completes the proof.

Remark 3.4 (1) Theorem 3.3 extends the main result of [6] from a uniformly smooth Banach space to a real Banach space and without the boundedness assumption of $D(T)=$ $R(T)$ and $\lim _{n \rightarrow \infty} a_{n}=\lim _{n \rightarrow \infty} b_{n}=0$; (2) Theorem 3.3 extends and improves the corresponding results of [7] by removing the assumptions $b_{n} \leq a_{n}$ and $\sum_{n=1}^{\infty} a_{n}^{2}<\infty$.

\section{Competing interests}

The authors declare that they have no competing interests.

Authors' contributions

All authors contributed equally to the writing of this paper. All authors read and approved the final manuscript.

Author details

'School of Applied Mathematics, Guangdong University of Technology, Guangzhou, 510520, China. ${ }^{2}$ School of Automation, Guangdong University of Technology, Guangzhou, 510006, China.

\section{Acknowledgements}

The authors thank the referees and the editor for their careful reading of the manuscript and their many valuable comments and suggestions for the improvement of this article. The first author was supported in part by the Humanity and Social Sciences Research Planning Foundation of Ministry of Education of China (Grant No. 14YJAZH095). The second author was supported by National Natural Science Foundation of China (Grant No. 61374081) and the Natural Science Foundation of Guangdong Province (Grant No. S2013010013034) 


\section{References}

1. Yao, Y, Postolache, M, Kang, SM: Strong convergence of approximated iterations for asymptotically pseudocontractive mappings. Fixed Point Theory Appl. 2014, Article ID 100 (2014)

2. Thakur, BS, Dewangan, R, Postolache, M: Strong convergence of new iteration process for a strongly continuous semigroup of asymptotically pseudocontractive mappings. Numer. Funct. Anal. Optim. 34(12), 1418-1431 (2013)

3. Thakur, BS, Dewangan, R, Postolache, M: General composite implicit iteration process for a finite family of asymptotically pseudocontractive mappings. Fixed Point Theory Appl. 2014, Article ID 90 (2014)

4. Tan, KK, Xu, HK: Approximating fixed points of nonexpansive mappings by the Ishikawa iteration process. J. Math. Anal. Appl. 178, 301-308 (1993)

5. Morales, C: Pseudocontractive mappings and Leray-Schauder boundary condition. Comment. Math. Univ. Carol. 20 745-746 (1979)

6. Chidume, CE: Global iteration schemes for strongly pseudo-contractive maps. Proc. Am. Math. Soc. 126, 2641-2649 (1998)

7. Osilike, MO: Iterative solutions of nonlinear $\phi$-strongly accretive operator equations in arbitrary Banach spaces. Nonlinear Anal. 36, 1-9 (1999)

8. Imoru, CO, Olatinwo, MO: On the stability of Picard and Mann iteration procedures. Carpath. J. Math. 19(2), 155-160 (2003)

9. Olatinwo, MO: Some stability and strong convergence results for the Jungck-Ishikawa iteration process. Creative Math. Inform. 17, 33-42 (2008)

10. Haghi, RH, Postolache, M, Rezapour, S: On T-stability of the Picard iteration for generalized $\phi$-contraction mappings. Abstr. Appl. Anal. 2012, Article ID 658971 (2012)

11. Olatinwo, MO, Postolache, M: Stability results for Jungck-type iterative processes in convex metric spaces. Appl. Math Comput. 218(12), 6727-6732 (2012)

12. Reich, S, Zaslavski, AJ: Genericity in Nonlinear Analysis. Springer, New York (2014)

13. Harder, AM, Hicks, TL: Stability results for fixed point iteration procedures. Math. Jpn. 33, 693-706 (1988)

14. Kato, T: Nonlinear semigroups and evolution equations. J. Math. Soc. Jpn. 19, 508-520 (1967)

15. Liu, QH: Iterative sequences for asymptotically quasi-nonexpansive mapping with error members. J. Math. Anal. Appl. 259, 18-24 (2001)

16. Osilike, MO: Stable iteration procedure for quasi-contractive maps. Indian J. Pure Appl. Math. 27, 25-34 (1996)

17. Rhoades, BE: Fixed point theorems and stability results for fixed point iteration procedures II. Indian J. Pure Appl. Math. 24,691-703 (1993)

10.1186/1687-1812-2014-224

Cite this article as: Yang and Peng: Convergence and stability of modified Ishikawa iteration sequence with errors. Fixed Point Theory and Applications 2014, 2014:224

\section{Submit your manuscript to a SpringerOpen ${ }^{\ominus}$ journal and benefit from:}

- Convenient online submission

- Rigorous peer review

- Immediate publication on acceptance

Open access: articles freely available online

- High visibility within the field

- Retaining the copyright to your article 